\title{
The Level of Awareness of Cardio- Pulmonary Resuscitation (CPR) Amongst Radiographers in Nigeria
}

\author{
Edomwonyi N. P. ${ }^{b}$ And E.E. Egbagbe ${ }^{b}$
}

\begin{abstract}
Resuscitation is one of the most evolving areas of modern medicine. For the past forty years newer techniques are developed in order to improve the outcome of resuscitation. The study is aimed at finding the level of knowledge amongst radiographers practising in Nigeria because radiographers use materials that commonly cause reactions requiring resuscitation. In an Annual conference of the Nigerian Radiographers held in Benin City, questionnaires were administered to eighty participants. Data extracted included age, gender, years of experience in practice and questions relating to resuscitation

Forty-five participants completed the questionnaires. 69\% (31) had witnessed cardiac arrest. 80\% (36) of them mentioned the causes of cardiac arrest, while 87\% (39) mentioned different types of resuscitation drugs. All the respondents mentioned the adverse reactions associated with the use of intravascular contrast media (ICM). Awareness of CPR amongst the observed Nigerian radiographers is rated high as evidenced by this study.
\end{abstract}

\section{INTRODUCTION}

The practice of cardiopulmonary resuscitation (CPR) dates back to biblical times ${ }^{1 .}$ In 2 Kings 4:34 prophet Elisha revived an apparently dead child using mouth to mouth breathing. Nevertheless it was not until 1954 that Elam et al demonstrated that mouth to mouth respiration (the kiss of life) with the operator's expired air was physiologically adequate to produce pulmonary ventilation ${ }^{2,3}$.

KEY WORDS: Awareness, Cardiopulmonary Resuscitation, Nigerian Radiographers

aDepartment of Anaesthesia, ${ }^{b}$ Department of Internal Medicine, University of Benin Teaching Hospital, Benin City, Edo State, Nigeria

Correspondence: Dr. N. P. Edomwonyi, Department of Anaesthesia, University of Benin Teaching Hospital, Benin City, Edo State, Nigeria
Though the method of internal defibrillation was described in 1933, its use was not possible until the development of external cross-chest defibrillation in 1956 and $1957^{\text {4,5. The modern }}$ era of CPCR began in 1960 in a paper authored by Kouwenhoven, Jude and Knickerboker entitled Close Chest Cardiac Compression, Artificial Ventilation and Electrical Defibri11ation. ${ }^{6}$

Cardiopulmonary arrest is the sudden cessation of spontaneous and effective ventilation and systemic perfusion ${ }^{7}$. Previously when the heart stops, a patient is considered dead. Presently it is known that certain procedures when carried out within four minutes would make the patient to survive ${ }^{8}$.

Severe reactions to radiographic contrast media can lead to significant patient morbidity or mortality. ${ }^{9}$ Radiographic contrast media are probably responsible for a greater

(.) CMS UNIBEN JMBR 2006; 5 (1) : 29-35 
number of adverse reactions than any other exclusively intravascular agent. ${ }^{10}$

This study was, therefore, aimed at finding the level of knowledge amongst radiographers practicing in Nigeria, attitude to the standard knowledge and level of practice of CPR.

\section{MATERIALS AND METHODS}

In an Annual/Scientific Conference of the Nigerian Radiographers which was held in Benin-City, Nigeria, between November $23^{\text {rd }}$ and $25^{\text {th }} 2004$, questionnaires were administered to the congress (eighty participants). The partici-pants came from different centres ranging from Teaching Hospitals, Federal Medical centres, General Hospitals, Private Hospitals and hospitals owned by companies and Federal school of Radiographers.

The questions were grouped into two broad groups, test of knowledge and test of practice. For test of knowledge, five questions were used. They were definition of cardiac arrest, causes of cardiac arrest, drugs used for management of cardiac arrest, types of intravenous contrast media (ICM) used in their centres and complications following the use of ICM. (Questions 7,8,10,12 and 13; see Appendix 1). The questions were scored and the scores were graded Excellent (80 - 100\%), Very Good (60 - 79\%), Good (50 - 59\%) and Poor $(<50 \%)$. The scores were used to assess their knowledge and practice.

Data extracted included age, gender, years of experience and questions related to resuscitation. Data was entered into Excel Spread Sheet and presented as frequency and percentages. Statistical analysis was done using ANOVA - Single factor. $\mathrm{P}<0.05$ was considered significant.

\section{RESULTS}

Forty-five (56.25\%) participants completed the questionnaires. Seventeen (27.8\%) of the participants were males while 28 (62.2\%) were females. Their ages ranged from 22 to 62 years. (Mean/S.D $=40 \pm 12$ ) (Table 1a).

\section{Table la - Sociodemographic Data}

$\begin{array}{ll}\text { Sex M/F } & -17 / 28 \\ \text { Age/yrs (mean/SD) } & -40 \pm 12 \\ \text { Yrs of Experience (mean/SD) } & -15 \pm 12\end{array}$

There are three institutions where radiography is offered in Nigeria. They are University of Calabar, University of Nigeria, Nnsuka and Federal School of radiographers, Lagos. The qualifications of the participants ranged from: Postgraduate Diploma (PGD) - 3, Masters of Business Administration (MBA) 4, Diploma, College of Radiographers (DCR) 13, Bachelors of Science in Radiography (BscRad) - 15, Masters of Science (MSc) - 5 , Diploma, Institute of Radiography (DIR) - 4, Masters in Health Planning and Management (MHP\&M) to Masters in Public Administration (MPA) - 1. Work experience ranged between a year and thirty - two years. (Mean/S.D = 15 +12) Table 16 shows the types of Institutions the participants work. $40 \%(\mathrm{n}=18)$ of them work in different Teaching Hospitals in the country. Table 2 shows the different complications (reactions) to intravascular contrast

\section{Table $1 b$ - Institutions/Hospitals where the Radiographers Work}

\begin{tabular}{|l|l|l|}
\hline S/N & Name of Institutions & Number of participants \\
\hline 1 & Teaching Hospitals & $18(40 \%)$ \\
2 & State Hospitals & $13(28.9 \%)$ \\
3 & Private Hospitals & $6(13.3 \%)$ \\
4 & Nigerian Federal School of Radiographer & $5(11.1 \%)$ \\
5 & Companies (Oil) [ Chevron, Agip Oil] & $3(6.7 \%)$ \\
\hline
\end{tabular}

( $C$ CMS UNIBEN JMBR 2006; 5 (1) : 29-35 
The Level of Awareness of Cardio - Pulmonary Resuscitation (CPR) Amongst Radiographers in Nigeria 31

media the participants had observed in patients during their practice. The commonly observed complications were cardiovascular 25 (33\%), gastrointestinal 23 (31\%), central nervous system $9(12 \%)$, respiratory 8 (11\%) and others 10 (13\%).

Tables $3 a$ and $3 b$ show test of knowledge and test of practice respectively. $71 \%$ (32) of the respondents scored $100 \%$ in the question on definition of cardiac arrest, 69\% had witnessed cardiac arrest in their practice, 87.5\% mentioned three drugs used for the management of cardiac arrest and $80 \%$ mentioned more than one complications associated with the use of intravascular contrast media. The cases of witnessed cardiac arrest were successfully managed by the anaesthetists and radiologists. The response to the question on causes of cardiac arrest was equally very good as they scored $60-80 \%$. For questions 8, 12 and 14, less than 50 percent of respondents scored 100 percent and this was considered statistically significant $(P=0.024,0.015$ and 0.003 respectively). For the other four questions, more than 50 percent of respondents scored

\section{Table 2: Complications Mentioned by Participants}

\begin{tabular}{|l|c|}
\hline Complication & No. of respondents that mentioned the complications \\
Central nervous system & 1 \\
Headache & 4 \\
Restlessness & 1 \\
Shivering & 1 \\
Unconsciousness & 2 \\
Fainting & $25(33 \%)$ \\
\hline Cardiovascular System & 10 \\
Cardiac arrest & 4 \\
Palpitation & 11 \\
Shock & $8(11 \%)$ \\
\hline Respiratory system & 3 \\
Bronchospasm & 3 \\
Dyspnoea & 1 \\
Aspiration of gastric content & 1 \\
Apnoea & $23(31 \%)$ \\
\hline Gastrointestinal & 20 \\
Vomiting & 13 \\
Nausea & $10(13 \%)$ \\
\hline Others & 3 \\
Itching & 3 \\
Urticarial rashes & 1 \\
Extravasation & 1 \\
Sweating & 1 \\
Hyperthermia & 1 \\
Allergy & \\
\hline
\end{tabular}

$75(100 \%)$ 
Table $3 a$ - Test of Knowledge

\begin{tabular}{|c|c|c|c|c|c|c|c|c|}
\hline $\begin{array}{l}\text { Scores } \\
\text { Question }\end{array}$ & $\begin{array}{l}100 \% \\
\text { No. of } \\
\text { Respondent } \\
(\%)\end{array}$ & $80 \%$ & $60 \%$ & $50 \%$ & $20 \%$ & $0 \%$ & \multicolumn{2}{|c|}{ P - value } \\
\hline $\begin{array}{l}7 \\
8 \\
10\end{array}$ & $\begin{array}{l}71 \%(32) \\
13 \%(6) \\
69 \%(31)\end{array}$ & $27 \%(12)$ & $40 \%(18)$ & $18 \%(8)$ & $11 \%(5)$ & $\begin{array}{l}29 \div(13) \\
9 \%(4) \\
13 \%(6)\end{array}$ & $\begin{array}{l}0.202 \\
0.024 \\
0.170\end{array}$ & $\begin{array}{l}\text { NS } \\
\text { S } \\
\text { NS }\end{array}$ \\
\hline Scores & $100 \%$ & $67 \%$ & $33 \%$ & $0 \%$ & & & & \\
\hline $\begin{array}{l}12 \\
13 \\
\end{array}$ & $\begin{array}{l}44 . \%(20) \\
64 \%(29)\end{array}$ & $\begin{array}{l}22 . \%(10) \\
22 . \%(10)\end{array}$ & $\begin{array}{l}24 \%(10) \\
7 \%\end{array}$ & $\begin{array}{l}9 \%(5) \\
7 \%(6) \\
\end{array}$ & & & $\begin{array}{l}0.015 \\
0.121 \\
\end{array}$ & $\begin{array}{l}\text { S } \\
\text { NS } \\
\end{array}$ \\
\hline Table $3 b$ - & $\begin{array}{l}\text { est of Practi } \\
100 \% \\
35.5 \%(16) \\
80 \%(36)\end{array}$ & $\begin{array}{l}67 \% \\
29 \%(13) \\
2 . \%(1)\end{array}$ & $\begin{array}{l}33 \% \\
11 \%(5)\end{array}$ & $\begin{array}{l}0 \% \\
24 \%(10) \\
18 \%(8)\end{array}$ & & & $\begin{array}{l}0.003 \\
0.137\end{array}$ & $\begin{array}{l}S \\
\text { NS }\end{array}$ \\
\hline
\end{tabular}

100 percent. $\mathrm{P}>0.05$.

S - Significant

NS - Not Significant

\section{Legend to Tables $3 a$ and $3 b$}

Questions

7 - What is cardiac arrest?

8 - Mention five causes of cardiac arrest

10 -Mention two drugs used for the management of cardiac arrest

12 - Mention three types of intravenous contrast media (ICM) used in their hospitals

13 - Mention three complications following the use of ICM

14 - How do you manage the complications mentioned in Question 13?

15 - $\mathrm{ABC}$ of resuscitation means what?

\section{DISCUSSION}

Resuscitation is one of the most evolving areas of modern medicine while cardiopulmonary resuscitation (CPR) is a treatment modality aimed at preventing sudden, unexpected death in life threatening situations. Basic life support refers to maintaining airway patency and supporting breathing and the circulation without the use of equipment other than a simple airway or protective shield. 6,11,12 Advanced life support as recommended by the European Guidelines entails the use of venous access, administration of adrenaline, the use of defibrillator for shockable rhythms and the identification and correction of reversible factors. ${ }^{13}$

Table 4 - Rating of the Questions

\begin{tabular}{|l|l|l|l|}
\hline Question & No. of Respondents & Range of scores & Rating \\
\hline 7 & $32(71.1 \%)$ & $100 \%$ & Excellent \\
8 & $36(80 \%)$ & $50-100 \%$ & Good/Excellent \\
10 & $39(68.9 \%)$ & $50-100 \%$ & Good/Excellent \\
12 & $30(66.7 \%)$ & $67-100 \%$ & Very good \\
13 & $39(86.7 \%)$ & $67-100 \%$ & Very good \\
14 & $29(64.4 \%)$ & $67-100 \%$ & Very good \\
15 & $37(82 \%)$ & $80-100 \%$ & Very good \\
\hline
\end{tabular}

(. CMS UNIBEN JMBR 2006; 5 (1):29-35 
The Level of Awareness of Cardio - Pulmonary Resuscitation (CPR) Amongst Radiographers in Nigeria 33

The group of radiographers who attended the conference is a representation of Nigerian radiographers. They work in different establishments and institutions in the country. In their different set up, they encounter different types of persons: healthy, unhealthy, and critically ill persons. They make use of contrast media in their centres and were able to enumerate the different types of contrast media as well as the complications associated with their uses.

The high level of awareness in this study group could be explained by the fact that they are continuously witnessing these events (complications associated with the use of contrast media) and had actually participated in the management of the cases.

Contrast media are salts formed by combining iodine-containing anions with various cations. Contrast media are hypertonic relative to plasma, with many agents having osmolarities above $1,100 \mathrm{mbm} / 1$. Injection of hyperosmolar solutions can produce a 10 to 12 percent increase in serum osmolarity and thus haemodynamic changes. Idiosyncratic reactions ranging from nausea and flushing to anaphylactiod shock and death can also occur following injection of contrast media. Hypotension and cardiac arrhythmias have been reported to be the first signs of Intravenous Contrast media (ICM) toxicity in 10 to 13 percent of fatal reactions. ${ }^{14}$ More cardiovascular complications were observed by the respondents in their centres. Lowasmolality contrast agents: Ioxaglate (Hexabrix), Ioxehol (omnipaque - 310), Lopamidol (Isovue - 300), Iopromide (Ultravist) are said to offer better tolerance and other advantages over older conventional agents. ${ }^{14,15}$

ICM can penetrate the blood-brain barrier in a dose-dependent manner and produce seizures. Mild reactions may be treated by the radiologist, with the anaesthesiologist being called on primarily to treat hypotension, bronchospasm, anaphylactoid reactions or seizures. ${ }^{15}$ It is mandatory to have resuscitation equipment (oxygen and source of giving it ; face mask, oropharyngeal airways, endotracheal tubes, laryngoscopes) and resuscitation drugs (adrenergic agonists, methylxanthines, anticholinergics, antihistamines, steroids and intravenous fluids) where ICM is used. ${ }^{15}$

Renal failure is another form of adverse reaction that is dependent on the dose of contrast material used. Renal failure following administration of contrast material occurs in 0.1 - 13\% of patients who received contrast material. ${ }^{16,17}$ Direct cellular toxicity and intrarenal vasoconstriction are believed to be the primary causes of renal function changes. ${ }^{17,18}$

The radiologists are usually the first physicians to evaluate a patient who is having a reaction and their decisions will have tremendous bearing on the subsequent management of the patient and the final outcome. Our study showed that the same practice obtains in Nigeria, where the radiologists manage mild complications, while the anaesthetists manage the moderate to severe complications. The witnessed cardiac arrests by the participants in their places of work were successfully resuscitated by the anaesthetists. Most reactions to contrast media occur within 30 minutes of injection. ${ }^{19}$ In a study, 94\% of severe and fatal reactions to contrast material occurred within 20 minutes of injection ${ }^{20}$ and more than $60 \%$ developed within the first 5 minutes. Many life-threatening reactions begin with only mild symptoms, such as nasal congestion, sneezing, watery eyes, skin erythema or a vague sense of discomfort. ${ }^{21}$ Guidelines have been developed by the American College of Radiology for the use of low-osmolality, non ionic agents. ${ }^{22}$

The anaesthetists in various hospitals in this country are always giving lectures on resuscitation. These lectures are directed towards improving the knowledge, attitude and practice of various health personnels in the hospitals. Oftentimes, practical demonstrations are given as well. This type of assessment of radiographers who are involved in CPR is important and helps to assess their 
34 Joumal of Medicine and Biomedical Research

level of knowledge, attitude and practice; particularly so that more lectures/demonstrations can be given by anaesthetists.

On the whole, knowledge can be rated as being high for the participants. The practice of resuscitation by the study group was rated as being very good.

\section{CONCLUSION}

Awareness of CPR amongst the observed Nigerian radiographers is rated high as evidenced by this study.

Radiologists, other physicians and radiology personnel who have direct contact with patients should be familiar with and certified in providing emergency care. Radiology departments must be equipped and their personnel trained to respond to lifethreatening reactions at any time.

\section{ACKNOWLEDGEMENT}

our gratitude to Prof. A. Obasohan for finding time to go through the paper and for his useful criticism. We wish to thank Engr. Ugieosa ImaEdomwonyi for helping with the statistical analysis and secretariat work.

\section{References}

1 The Holy Bible. 2 Kings 4:34 (Kings James Version) .

2 Elam J.O, Brown E.S, Elder J.D. Jr. "Artificial respiration by mouth to mask method. A study of the respiratory gas exchange of paralyzed patients ventilated by operators expired air" . N Engl J Med 1954;250: 749 754.

3. Safar P, Escarragah A, Elam J.O. "A comparison of the mouth to mouth and mouth - to - airway methods of artificial respiration with the chest - pressure arm lift methods". N Engl J Med 1958; 258: 671 $-677$.

4 Zoll P.M, Linenthal A.J, Gibson W et al. "Termination of ventricular fibrillation in man by an externally applied electric shock" . N Engl J Med 1956; 254: 727 - 732 .
5. Kouwenhoven W.B, Milnor W.R, Kinckerbocker G.G, Chestnut W.R. "Closed chest defibrillation of the chest". Surgery 1957; $42: 550-561$.

6. Redding J.S, Pearson J.W. "Evaluation of drugs for cardiac resuscitation". Anaesthesiology 1963; 24:203- 207.

7. Watkins J. Anaphylactoid reactions to I.V. substances. Br. J. Anaesth. 1979; 51: $51-60$.

8. Marsden A. K. "Basic Life Supports" . Revised Recommendation of the Resuscitation Council. Medical J. 1989; 299:442 445.

9. Safar P. "Cardiopulmonary Cerebral Resuscitation". Philadelphia: W.B. Saunders Co. 1981.

10. Emergency Cardiac Care Committee and Subcommittees. America Heart Associa-tion guidelines for Cardiopul-monary Resuscitation and Emergency Cardiac Care. J. of Am. Med. Assoc. 1992; 268:2171 - 2302 .

11. Goldberg M. "Systematic reactions to intravascular contrast media. A guide for the anaesthesiologist". Anaesthesiology 1984; 60: 46 .

12. Recommended guidelines for uniform reporting of data from out - of - hospital cardiac arrest: the 'Utstein style' . Prepared by a task force of representatives from the European Resuscitation Council, American Heart Association, Heart and stroke Foundation of Canada, Australian resuscitation Council. Resuscitation 1991;22:1-26.

13. Jerry P.Nolan, Charles D.Deakin, Jasmeet Soar, Bernd W. Bottigier, Gray Smith. European Resuscitation Council Guidelines for Resuscitation 2005. Adult advanced life support. Resuscitation 2005;675:539586.

14. Smith D.C, Yahiku P.Y, Maloney M.D et al: Three new low-osmolality contrast agents: A comparative study of patient discomfort, JNR 9:137, 1988.

15. Maddox T.G. Adverse Reactions to Contrast Material: Recognition, Prevention and 
The Level of Awareness of Cardio - Pulmonary Resuscitation (CPR) Amongst Radiographers in Nigeria 35

Treatment. American Family Physician, $2002 ; 66: 1229-34$

16. Quader MA, Sawmiller C, Sumpio BA. Contrast-induced nephropathy: review of incidence and pathophysiology. Ann Vasc. Surg. 1998. 12:612-20.

17. Marcos SK, Contrast media-induced nephrotoxicity- questions and answers. Br J Radiol 1998; 71:357 - 65.

18. Teoel M, Zidek W, Acetylcysteine and contrast media nephropathy. Curr. Opin Nephrol Hypertens 2002 ; 11 :503-6
19. Skalpe I.O: Complications in cerebral angiography with iohexol (Omnipaque) and meglimine metrizoate. (Isopaque cerebral) . Neuroradiology 1988, 30:69

20. Netzel MC. Anaphylaxis: Clinical presentations immunologic mechanisms and treatment. J Emerg Med 1986; 4: 227 - 236.

21. Ansell G. An epidemiologica report on adverse reactions in urography: ionic and nonionic media. Diagn Imag 1987; Mory (suppl) : $5-10$.

22. Manual on contrast media. Ed. 4.1, 1998. Reston, Va - American college of Radiology, 2001. 